\title{
An unusual case of penetrating tracheal ("Cut throat") injury due to chain snatching: The ideal airway management
}

\author{
Sengoda Gounder Venkatachalam, D. A. Palaniswamy Selvaraj, Muthukumaran Rangarajan, \\ Kumarasami Mani, Chinnusamy Palanivelu
}

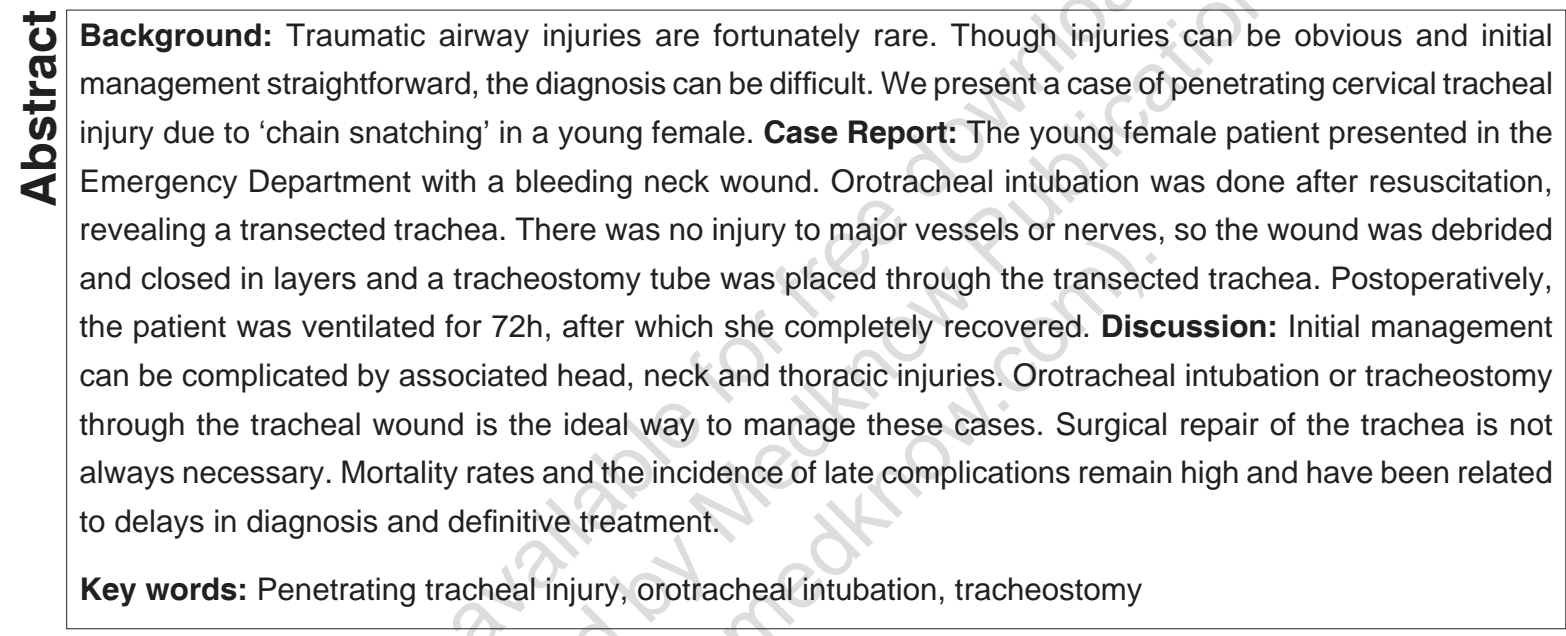

\section{Introduction}

Penetrating airway injuries in the neck are also relatively uncommon, accounting for an average of less than three cases per year per reporting center. ${ }^{[1]}$ Penetrating injuries of the neck involve the larynx in $5-15 \%$ of patients, associated carotid artery or digestive track injuries being twice as likely to have airway injuries. ${ }^{[2]}$ The prevailing site of tracheal transection is the junction of the cricoid with the trachea, because the connective tissues in this area are weak. ${ }^{[3]}$ We present a patient who was the victim of a violent crime - chain snatching. She had an obvious cervical tracheal injury. Since this type of injury is quite

\footnotetext{
From:

GEM Hospital, 45-A, Pankaja Mill Road, Ramnathapuram, Coimbatore - 641 045, India

Correspondence:

Dr. Palaniswamy Selvaraj, GEM Hospital, 45-A, Pankaja Mill Road,

Ramnathapuram, Coimbatore - 641045 , India

E-mail: rangy68@gmail.com
}

rare, we briefly reviewed the literature and present our views.

\section{Case Report}

The patient was a 25-year-old lady admitted with alleged history of chain snatching while she was traveling as a pillion on a motorbike with her husband. Since her neck started bleeding, compression was applied around her neck by her husband using her own sari, to arrest the bleeding [Figure 1]. She was brought to our hospital Emergency Department with dyspnea orthopnea, severe pain around the neck, difficulty in swallowing and difficulty in phonation. There was no significant medical illness in the past. On examination, the patient was conscious, restless, dyspnoeic, tachypnoeic, anemic and in shock. Pulse rate was 167/minute, systolic blood pressure was $60 \mathrm{mmHg}, \mathrm{SaO}_{2}$ not recordable, cardiovascular system showed evidence of unstable hemodynamics, respiratory 


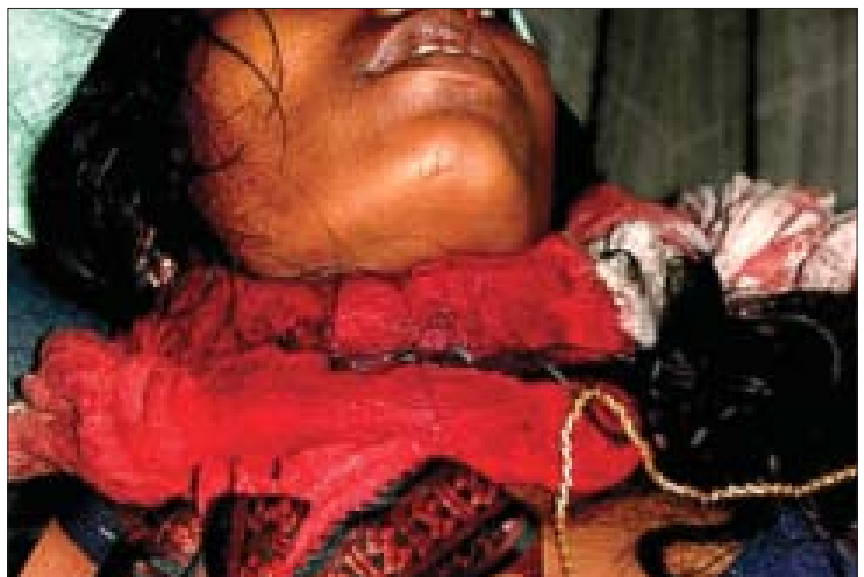

Figure 1: First aid by patient's husband - compression of wound using sari

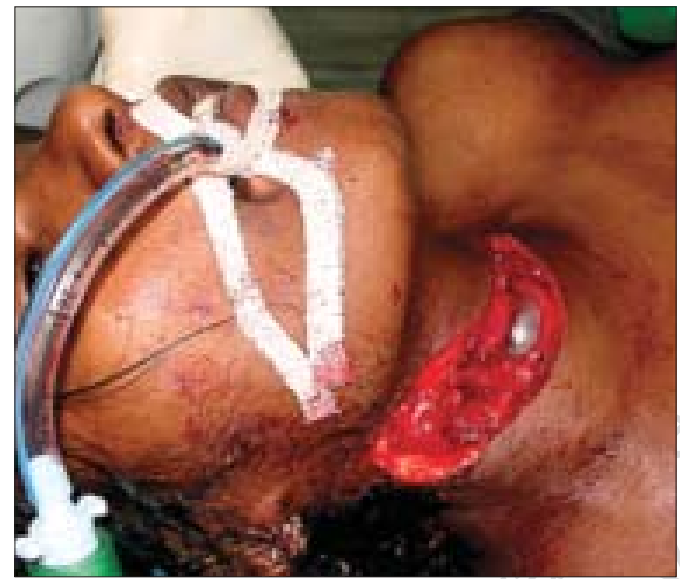

Figure 2: Orotracheal intubation (cuff of the endotracheal tube visible in the neck wound)

system showed bilateral crepitations and wheezing. The abdomen was normal on examination. Management was commenced by first inserting two wide bore (16 g) intravenous cannulae in the antecubital fossa of each arm through which $1000 \mathrm{ml}$ crystalloid and $500 \mathrm{ml}$ of colloid were administered. Blood samples were taken for routine investigations. Four units of blood and two units of fresh frozen plasma (FFP) were arranged. Within 20 minutes, the anesthesiologist examined the patient and immediately intubated her orotracheally [Figure 2] and put her on full ventilatory support (awake intubation under topical analgesia). On laryngoscopy, the entire oropharyngeal area was seen to be flooded with blood, which could not be controlled by routine oropharyngeal suctioning. After intubation, the endotracheal tube was filled with aspirated blood, which was removed by endotracheal suctioning. A nasogastric tube was placed in the esophagus under vision. Since the site of injury was the neck, it was decided to examine the patient in



Figure 3: "Cut-throat" injury with sliced trachea; cuff of the endotracheal tube (small arrow); causative agent - gold chain (large arrow)

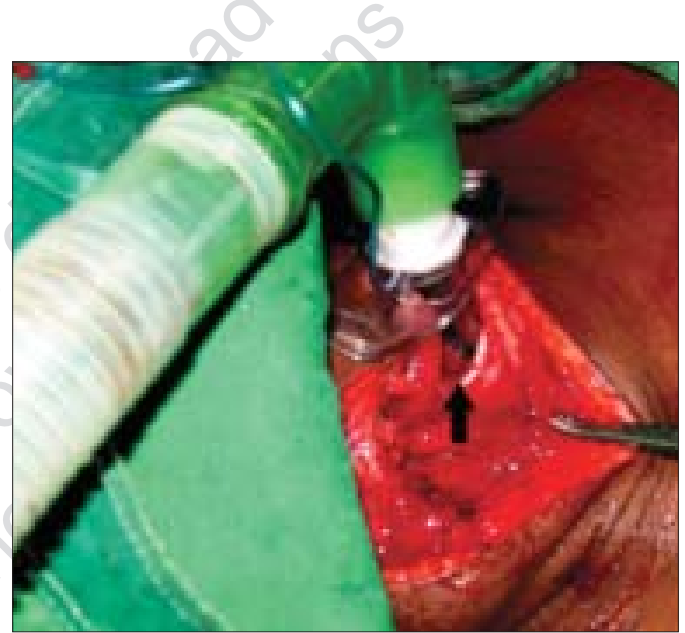

Figure 4: Tracheostomy tube inserted into the partially transected trachea (arrow)

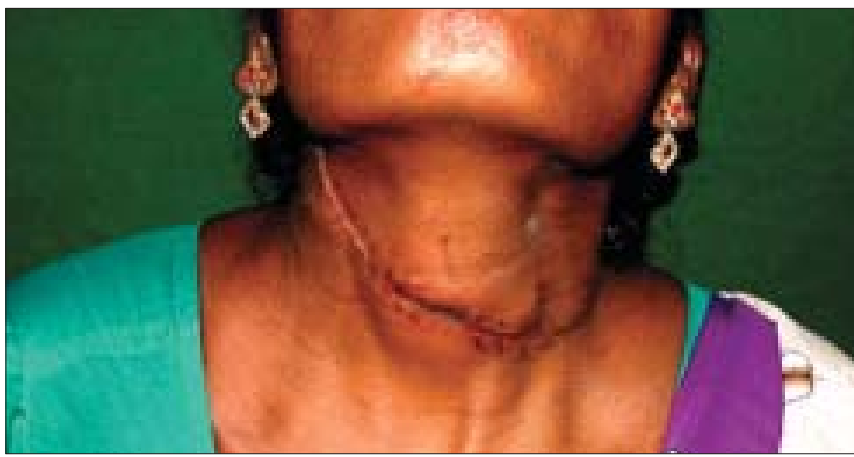

Figure 5: $14^{\text {th }}$ postoperative day shows wound healed well

the operation theatre under general anesthesia, so she was shifted supported by ambu-assisted ventilation. Anesthesia was induced with ketamine $50 \mathrm{mg}$ IV and atracurium $20 \mathrm{mg}$ IV and 100\% oxygen. Maintenance was done with oxygen:nitrous oxide (50:50), $40 \mathrm{mcg}$ of fentanyl and atracurium. When the compressive pack was removed from the neck wound, there was no large vesse 
bleed but there was diffuse bleedings from minor vessels. The cuff of the endotracheal tube was seen protruding out of the partially transected trachea [Figure 3]. After achieving hemostasis, a 7.0-size cuffed tracheostomy tube was inserted after removing the endotracheal tube [Figure 4]. The site of injury was below the level of the cricothyroid membrane and the trachea was partially transected in the anterior $2 / 3$ region, while the posterior $1 / 3$ was intact. On either side of the tracheostomy tube, a single suture was applied to reduce the gap, in order to prevent aspiration. The thyroid gland was partially injured (bleeding points were identified and hemostasis achieved). There were no obvious nerve or esophageal injuries. The wound was thoroughly irrigated with saline and antiseptic solutions and closed in layers after placing a drain tube. Postoperative management was provided in the ICU.

\section{Results}

At the end of the procedure, the patient was electively ventilated for $72 \mathrm{~h}$. During this time, serial chest $\mathrm{X}$ rays and hematological examinations were observed daily. The patient was weaned off from the ventilator after 72h. Ambulation was encouraged, supported by physiotherapy. The tracheostomy was removed on the seventh postoperative day (POD) and allowed to heal spontaneously. After that, she had some hoarseness of voice but was able to speak normally later. She was fed with liquids through the nasogastric tube after $24 \mathrm{~h}$ following surgery and orally on the eight POD. The patient was discharged on the $14^{\text {th }}$ POD after confirming that the tracheostomy wound healed well [Figure 5] and swallowing/cough reflexes were adequate. At the next follow-ups after 24 and 38 months, the patient was asymptomatic and doing well.

\section{Discussion}

Only a minority of laryngotracheal injuries are caused by penetrating trauma. In our patient, the penetrating injury was caused by forcibly pulling on the gold chain for the purpose of theft ('chain snatching'). Indian ladies have the habit of wearing thick gold chains around the neck as a sign of wedlock. These thick chains will not break easily when snatched, thereby increasing the risk of neck trauma. Injuries to other structures include major or minor vessels, nerves, thyroid and esophagus and is the main reason for mortality (15-30\%). ${ }^{[4]}$ The possible mechanism for carotid sparing in our patient would be the backwardly thrown head at the time of injury, which is likely to draw the carotid sheath backwards. Radiography alone is not sufficient for diagnosing cervical airway trauma and the additional use of CT scan of the trachea and larynx and MRI can be very useful in discovering subtle, previously undetected injuries. ${ }^{[5]}$ Gonzalez et al., in a prospective blinded study, showed that dynamic CT scan in penetrating neck injury was sensitive in diagnosing associated injuries. ${ }^{[6]}$ They however concluded that the majority of these injuries do not require identification or surgical intervention. Either way, definitive airway management should not be delayed excessively by radiologic studies, since an apparently stable airway can rapidly progress to an acute airway obstruction. This was the reason why we did not subject our patient to radiography or any imaging procedure. Many patients with upper airway injuries may be successfully managed using traditional techniques to establish an airway - intubation through an obvious airway defect or endotracheal/orotracheal intubation or tracheostomy. ${ }^{[7]}$ When the trachea itself is injured, it is preferable to conserve normal trachea by placing the tracheostomy through the damaged area, like we did for our patient. This will facilitate subsequent surgical repair of the trachea. However in our patient, the trachea was not surgically repaired, instead it was allowed to heal spontaneously. Nonsurgical management of tracheal injuries have been reported in the literature. ${ }^{[8]}$ These patients usually suffer some permanent airway or voice impairment and may have increased difficulties protecting the airway from aspiration of pharyngeal contents, though our patient had no such problems. Regional anesthesia can be tried but the disadvantages are that bilateral vagal block often produce concomitant block of hypoglossal nerve leading to flaccidity of tongue, which might further obstruct the pharyngeal airway and could abolish all the protective reflexes of lower airway. ${ }^{[9]}$ Moreover, these methods are also technically difficult to perform. The preferred technique is awake intubation through the mouth by the conventional method under topical analgesia. ${ }^{[10]}$ Some of the problems encountered during general anesthesia are anatomical distortion of the neck and tracheal displacement making intubation difficult; intravenous induction agents producing hypotension, which is undesirable for a bleeding patient; and danger of vomiting and aspiration. Inhalation induction is also difficult, due to partial breathing 'through the neck' and uncertain control of airway. ${ }^{[11]}$ Postoperative care includes fluid balance to prevent dehydration; humidification 
and aspiration of tracheobronchial secretions; cuff pressure monitoring; and broad-spectrum antibiotics. To summarize, penetrating tracheal injuries are rare. The ideal way to establish airway is orotracheal intubation in the awake patient followed by placement of a tracheostomy tube through the transected portion of the trachea. Formal surgical repair is not mandatory in all cases, as in this patient the tracheostomy wound healed spontaneously. In the end, our patient recovered completely, only psychological scars remained.

In conclusion, even though these types of penetrating tracheal injuries are not common, managing them successfully is often a challenge. These incidents remind us of the violent world we live in and that accident and emergency specialists must be prepared to deal with situations like these.

\section{References}

1. Symbas PN, Hatcher CR Jr, Boehm GA. Acute penetrating tracheal trauma. Ann Thorac Surg 1976;22:473-7.

2. Rao BK, Singh VK, Ray S, Mehra M. Airway management in trauma. Indian J Crit Care Med 2004;8:98-105.

3. Cicala RS, Kudsk KA, Butts A, Nguyen H, Fabian TC. Initial evaluation and management of upper airway injuries in trauma patients. J Clin Anesth 1991;3:91-8.
4. Grewal H, Rao PM, Mukerji S, Ivatury RR. Management of penetrating laryngotracheal injuries. Head Neck 1995;17:494502.

5. Rao PM, Novelline RA, Dobins JM. The spherical endotracheal tube cuff: A plain radiographic sign of tracheal injury. Emerg Radiol 1996;3:87-90.

6. Gonzalez RP, Falimirski M, Holevar MR, Turk B. Penetrating zone II neck injury: Does dynamic computed tomographic scan contribute to the diagnostic sensitivity of physical examination for surgically significant injury? A prospective blinded study. J Trauma 2003;54:61-5.

7. Beiderlinden M, Adamzik M, Peters J. Conservative treatment of tracheal injuries. Anesth Analg 2005;100:210-4.

8. Glinjongol C, Pakdirat B. Management of tracheobrochial injuries: A 10-year experience at Ratchaburi hospital. J Med Assoc Thai 2005;88:32-40.

9. Rossbach MM, Johnson SB, Gomez MA, Sako EY, Miller OL, Calhoon JH. Management of Major Tracheobronchial Injuries: A 28-Year Experience. Ann Thorac Surg 1998;65:182-6.

10. Peralta R, Hurford WE. Airway trauma. Int Anesthesiol Clin 2000;38:111-27.

11. Hurford WE, Peralta R. Management of tracheal trauma. Can J Anesthesia 2003;50:R1-6.

Source of Support: Nil, Conflict of Interest: None declared.

\section{Author Help: Reference checking facility}

The manuscript system (www.journalonweb.com) allows the authors to check and verify the accuracy and style of references. The tool checks the references with PubM ed as per a predefined style. Authors are encouraged to use this facility before submitting articles to the journal.

- The style as well as bibliographic elements should be $100 \%$ accurate to get the references verified from the system. A single spelling error or addition of issue number / month of publication will lead to error to verifying the reference.

- $\quad$ Example of a correct style Sheahan P, O'leary G, Lee G, Fitzgibbon J. Cystic cervical metastases: Incidence and diagnosis using fine needle aspiration biopsy. Otolaryngol Head Neck Surg 2002;127:294-8.

- $\quad$ Only the references from journals indexed in PubM ed w ould be checked.

- $\quad$ Enter each reference in new line, without a serial number.

- $\quad$ Add up to a maximum 15 reference at time.

- If the reference is correct for its bibliographic elements and punctuations, it will be show $n$ as CORRECT and a link to the correct article in PubM ed will be given.

- If any of the bibliographic elements are missing, incorrect or extra (such as issue number), it will be show $n$ as INCORRECT and link to possible articles in PubM ed will be given. 